\title{
Role of the lateral preoptic area in cardiovascular and neuroendocrine responses to acute restraint stress in rats
}

\author{
Josiane O. Duarte ${ }^{\mathrm{a}, \mathrm{b}, 1}$, Karina S. Gomes ${ }^{\mathrm{a}, 1}$, Ricardo L. Nunes-de-Souza ${ }^{\mathrm{a}, \mathrm{b}}$, Carlos C. Crestani ${ }^{\mathrm{a}, \mathrm{b}, *}$ \\ a Laboratory of Pharmacology, São Paulo State University (UNESP), School of Pharmaceutical Sciences, Araraquara, SP, Brazil \\ b Joint UFSCar-UNESP Graduate Program in Physiological Sciences, São Carlos, SP, Brazil
}

\section{A R T I C L E I N F O}

\section{Keywords:}

\section{LPO}

\section{Hypothalamus}

Heart rate

Blood pressure

HPA axis

Corticosterone

Stress

\begin{abstract}
A B S T R A C T
The lateral preoptic area (LPO) is connected with limbic structures involved in physiological and behavioral responses to stress. Accordingly, exposure to stressors stimuli activates neurons within the LPO. In spite of these evidence, an involvement of the LPO on cardiovascular and neuroendocrine adjustments during aversive threats has not yet been investigated. Therefore, in the present study we tested the hypothesis that the LPO is involved in the control of cardiovascular and neuroendocrine responses to acute restraint stress in rats. Bilateral microinjection of the nonselective synaptic blocker $\mathrm{CoCl}_{2}(0.1 \mathrm{nmol} / 100 \mathrm{nl})$ into the LPO did not affect basal values of either arterial pressure, heart rate, tail skin temperature, or plasma corticosterone concentration. However, LPO treatment with $\mathrm{CoCl}_{2}$ enhanced the tachycardiac response and the increase in plasma corticosterone concentration caused by restraint stress. Conversely, LPO synaptic blockade decreased restraint-evoked pressor response. Sympathetic-mediated cutaneous vasoconstriction during restraint stress was not affected by LPO pharmacological treatment. These findings indicate an inhibitory influence of LPO on tachycardiac and plasma corticosterone responses evoked during aversive threats. Additionally, data suggest that LPO plays a facilitatory influence on stress-evoked pressor response.
\end{abstract}

\section{Introduction}

Physiological adjustments during aversive threats are essential to the survival and well-being of all species $[1,2]$. The autonomic nervous system promotes the immediate responses to stress, which include blood pressure and heart rate (HR) increase, redistribution of blood flow (reduction to skin and viscera and increase for skeletal muscle), and a resetting of baroreflex toward higher arterial pressure values [3-5]. The cutaneous vasoconstriction during stress leads to a fall in the skin temperature [6-8]. Activation of the hypothalamic-pituitary-adrenocortical (HPA) axis is a primary neuroendocrine response during stressor exposure, which results in increased levels of circulating glucocorticoids [2].

The set of physiological adjustments during emotional stress is coordinated by activation of overlapping limbic circuits $[1,2,5]$. Neural connections have been described between limbic structures and the lateral preoptic area (LPO) [9]. Accordingly, activation of neurons in the LPO has been reported following exposure to different stressor stimuli (e.g., restraint stress, novel environment, and swim stress) $[10,11]$. Taken together, these pieces of evidence indicate that LPO can be part of the brain circuitry involved in stress responses. However, to the best of our knowledge, a possible involvement of the LPO in cardiovascular and neuroendocrine adjustments during aversive threats has not yet been investigated. In fact, a role of areas in the medial side of the preoptic area (such as the medial preoptic area) in stress-evoked neuroendocrine responses is well documented $[2,12,13]$, but evidence of an involvement of the LPO is missing.

Microinjection of glutamate into the LPO decreased HR while local microinjection of GABAergic agonists evoked opposite responses [14]. Moreover, treatment of the preoptic area, including the LPO, with GABA increased tail sympathetic nerve activity [15], which in turn decreased tail skin temperature [14]. Results have also indicated an inhibitory influence of the LPO on HPA axis activity [16]. Based on the aforementioned evidence, in the present study we tested the hypothesis that LPO plays an inhibitory role on stress-evoked physiological responses. To this end, we investigated the effects of LPO treatment with the nonselective synaptic inhibitor $\mathrm{CoCl}_{2}$ on autonomic (arterial pressure and HR increase and decrease in tail skin temperature) and neuroendocrine (plasma corticosterone increase) responses evoked in rats submitted to an acute session of restraint stress. Restraint stress is a

\footnotetext{
* Corresponding author at: Laboratory of Pharmacology, Department of Natural Active Principles and Toxicology, School of Pharmaceutical Sciences, Univ. Estadual Paulista-UNESP, Rodovia Araraquara-Jau Km 01 s/n, 14800-903 Araraquara, SP, Brazil.

E-mail address: cccrestani@yahoo.com.br (C.C. Crestani).

${ }^{1}$ These authors contributed equally to this work.
} 
widely employed stressor to evaluate behavioral and physiological changes evoked by aversive stimuli in laboratory animals [17].

\section{Material and methods}

\subsection{Animals}

Experimental procedures were carried out following protocols approved by the Ethical Committee for Use of Animals of the School of Pharmaceutical Science/UNESP. Adult male Wistar rats weighing approximately $250 \mathrm{~g}$ were used in the present study. Animals were obtained from the animal breeding facility of the State University Paulista-UNESP (Botucatu, SP, Brazil) and were housed in plastic cages in a temperature-controlled room $\left(24^{\circ} \mathrm{C}\right)$ in the Animal Facility of the Laboratory of Pharmacology/School of Pharmaceutical Sciences/ UNESP. Animals were kept under a 12:12 h light-dark cycle (lights on between 7:00 $\mathrm{h}$ and 19:00 $\mathrm{h}$ ) and had free access to water and standard laboratory food, except during the experimental period.

\subsection{Surgical preparation}

Five days before the experiment all rats were anesthetized with tribromoethanol (250 mg/kg, i.p.). After scalp anesthesia with $2 \%$ lidocaine, the skull was exposed and a stainless-steel guide cannula (26G) was implanted bilaterally into the LPO at a position $1 \mathrm{~mm}$ above the site injection, using a stereotaxic apparatus (Stoelting, Wood Dale, Illinois, USA). Stereotaxic coordinates for cannula implantation were: $\mathrm{AP}=+7.8 \mathrm{~mm}$ from interaural; $\mathrm{L}=4.0 \mathrm{~mm}$ from the medial suture, $\mathrm{V}=-7.0 \mathrm{~mm}$ from the skull with a lateral inclination of $20^{\circ}$ [20]. Cannulas were fixed to the skull with dental cement and one metal screw. After the surgery, the animals received a poly-antibiotic formulation with streptomycins and penicillins to prevent infection $(560 \mathrm{mg} / \mathrm{ml} / \mathrm{kg}, \mathrm{i} . \mathrm{m}$.) and the nonsteroidal anti-inflamatory flunixine meglumine to provide postoperative analgesia $(0.5 \mathrm{mg} / \mathrm{ml} / \mathrm{kg}$, s.c.).

One day before the trial, all animals were anesthetized with tribromoethanol $(250 \mathrm{mg} / \mathrm{kg}$, i.p.) and a catheter (a $4 \mathrm{~cm}$ segment of PE-10 heat-bound to a $13 \mathrm{~cm}$ segment of PE-50) (Clay Adams, Parsippany, NJ, USA) filled with a solution of heparin $(50 \mathrm{UI} / \mathrm{ml}$, Hepamax-S ${ }^{\circledast}$, Blausiegel, Cotia, SP, Brazil) was inserted into the abdominal aorta through the femoral artery for cardiovascular recording and blood sampling. The catheter was tunneled under the skin and exteriorized on the animal's dorsum. After surgery, the non-steroidal anti-inflammatory flunixine meglumine was administered to provide postoperative analgesia $(0.5 \mathrm{mg} / \mathrm{ml} / \mathrm{kg}$, s.c.). The animals were kept in individual cages during the post-operative period and experimental procedures.

\subsection{Measurement of arterial pressure and heart rate}

The cannula implanted into the femoral artery was connected to a pressure transducer (DPT100, Utah Medical Products Inc., Midvale, UT, USA). Pulsatile arterial pressure was recorded using an amplifier (Quad Bridge Amp, ML224, ADInstruments, NSW, Australia) and an acquisition board (PowerLab 4/30, ML866/P, ADInstruments, NSW, Australia) connected to a personal computer. Mean arterial pressure (MAP) and heart rate (HR) values were derived from pulsatile arterial pressure recordings.

\subsection{Tail cutaneous temperature measurement}

The tail cutaneous temperature was recorded using a thermal camera Multi-Purpose Thermal Imager (IRI4010, InfraRed Integrated Systems Ltd., Northampton, UK). The temperature measurement was performed on five points of the animal's tail and the mean value was calculated for each recording $[6,18]$.

\subsection{Plasma corticosterone measurement}

Plasma corticosterone concentration was measured by radioimmunoassay. The method was adapted from that described by Sarnyai, Biro [19]. Briefly, $20 \mu \mathrm{l}$ of plasma was diluted 50 times with $0.01 \mathrm{M}$ PBS and placed in a water bath at $75^{\circ} \mathrm{C}$ for $1 \mathrm{~h}$ for heat inactivation of corticosteroid binding globulin. One hundred microliters of a solution of antibody (Sigma-Aldrich, USA) and (3H)-corticosterone $(10,000-20,000 \mathrm{cpm} / \mathrm{ml})$ (New England Nuclear, Boston, MA, USA) was added to each sample, mixed and incubated overnight at $4{ }^{\circ} \mathrm{C}$. Dextran-coated charcoal was used to adsorb free steroid after incubation. Tubes were centrifuged at $2000 \times g$ for $15 \mathrm{~min}$ at $4{ }^{\circ} \mathrm{C}$, the supernatant from each tube was transferred to scintillation vials and the radioactivity was quantified by liquid scintillation spectrometry. Standard curves were constructed using 25, 50, 100, 250, 500, 750, 1000 and $2000 \mathrm{pg} / 100 \mu \mathrm{l}$ of corticosterone (Sigma-Aldrich, USA). After dilution, all concentrations of corticosterone samples were within the linear range of the standard curve.

\subsection{Restraint stress}

Restraint stress consisted in placing each rat into a plastic cylindrical restraint tube (diameter $6.5 \mathrm{~cm}$, length $15 \mathrm{~cm}$ ), ventilated by holes ( $1 \mathrm{~cm}$ diameter) that comprised approximately $20 \%$ of the tube surface. Restraint stress lasted for $30 \mathrm{~min}$, and immediately after the end of the session rats were returned to their home cages. Each rat was submitted to only one session of restraint in order to avoid habituation.

\subsection{Drug microinjection into the $L P O$}

Bilateral microinjections were performed into the LPO using a $2 \mu \mathrm{l}$ syringe $(7002 \mathrm{KH}$, Hamilton, USA), which was connected to the microinjection needle (33G, Small Parts, USA) through a PE-10 tubing. The needle used for microinjection into the LPO was $1 \mathrm{~mm}$ longer than the guide cannulas.

For the bilateral microinjection, the needle was carefully inserted into one of the guide cannulas (left or right, randomly) without restraining the animals, and the drug was injected within a $5 \mathrm{~s}$ period. After the microinjection, the needle was left into the guide cannula for $30 \mathrm{~s}$. Afterwards, the needle was removed and inserted into the contralateral guide cannula, and the microinjection procedure was repeated. Drugs were injected in a volume of $100 \mathrm{nl} /$ brain side.

\subsection{Drugs and solutions}

$\mathrm{CoCl}_{2}$ (Sigma-Aldrich, St. Louis, Missouri, USA), tribromoethanol (Sigma-Aldrich) and urethane (Sigma-Aldrich) were dissolved in saline ( $\mathrm{NaCl} 0.9 \%$ ). Flunixine meglumine (Banamine ${ }^{\circledR}$, Schering Plough, Cotia, SP, Brazil) and the polyantibiotic preparation of streptomycins and penicillins (Pentabiotico ${ }^{\oplus}$, Fort Dodge, Campinas, SP, Brazil) were used as provided.

\subsection{Experimental design}

Rats were brought to the experimental room in their own cages. Animals were allowed at least $60 \mathrm{~min}$ to adapt to experimental room conditions, such as sound and illumination, before starting the experiment. The experimental room was temperature controlled $\left(24^{\circ} \mathrm{C}\right)$ and acoustically isolated from other rooms. All experiments were performed during the morning period in order to minimize possible circadian rhythm interferences.

Independent set of animals received bilateral microinjections of the nonselective synaptic inhibitor $\mathrm{CoCl}_{2}(0.1 \mathrm{nmol} / 100 \mathrm{nl}, n=6)$ or vehicle (saline, $100 \mathrm{nl}, n=6$ ) into the LPO. Ten minutes after LPO treatment, the animals underwent a 30 min session of restraint stress.

Cardiovascular recording began at least $30 \mathrm{~min}$ before the onset of 
the restraint and was performed throughout the period of exposure to the restraint stress. Other measurements began only when the arterial pressure and heart rate were stables. The tail skin temperature was measured 10, 5 and $0 \mathrm{~min}$ before the restraint for baseline values, and 10,20 , and $30 \mathrm{~min}$ after the onset of the restraint. Blood samples $(\sim 200 \mu \mathrm{l})$ were collected from the femoral artery catheter immediately before (basal level) and at times 10 and $30 \mathrm{~min}$ during the restraint stress.

\subsection{Histological determination of the microinjection sites}

At the end of experiments, animals were anesthetized with urethane (1.25 g/kg i.p.) and $100 \mathrm{nl}$ of $1 \%$ Evan's blue dye was injected into the brain as a marker of microinjection site. Brains were removed and postfixed in $10 \%$ formalin for at least $48 \mathrm{~h}$ at $4{ }^{\circ} \mathrm{C}$. Then, serial $40 \mu \mathrm{m}$-thick sections of the LPO region were cut with a cryostat (CM1900, Leica, Wetzlar, Germany). The actual placement of the microinjection needles was determined upon analysis of serial sections and identified according to the rat brain atlas of Paxinos and Watson [20].

\subsection{Statistical analysis}

Data are presented as mean \pm SEM. The basal values of MAP, HR, tail skin temperature, and plasma corticosterone concentration were compared using Student's $t$-test. The time-course curves of changes in plasma corticosterone concentration and cardiovascular parameters were analyzed using two-way ANOVA, with treatment as main factor and time as repeated measurement. The significance was set at $P<0.05$.

\section{Results}

\subsection{Determination of the microinjection sites}

Fig. 1 presents diagrammatic representations showing microinjection sites of vehicle or the nonselective synaptic blocker $\mathrm{CoCl}_{2}$ into the LPO of all animals used in the present study.

\subsection{Effect of LPO treatment with $\mathrm{CoCl}_{2}$ on basal levels of MAP, HR, tail skin temperature, and plasma corticosterone concentration}

Bilateral microinjection of the nonselective synaptic blocker $\mathrm{CoCl}_{2}$ into the LPO $(0.1 \mathrm{nmol} / 100 \mathrm{nl}, n=6)$ did not affect baseline values of either MAP $(108 \pm 2$ vs $107 \pm 6 \mathrm{mmHg}, t=0.2, P>0.05)$, HR (395 \pm 23 vs $398 \pm 21 \mathrm{bpm} ; t=0.09, P>0.05$ ), tail skin temperature $\left(29.6 \pm 0.9\right.$ vs $\left.27.0 \pm 0.7^{\circ} \mathrm{C} ; t=2, P>0.05\right)$, or plasma corticosterone concentration $(13 \pm 2$ vs $18 \pm 4 \mu \mathrm{g} / \mathrm{dl} ; t=0.9$, $P>0.05)$, when compared with vehicle-treated animals $(n=6)$.

\subsection{Effect of $L P O$ treatment with $\mathrm{CoCl}_{2}$ in autonomic and neuroendocrine} responses evoked by acute restraint stress

Acute restraint stress induced a marked and sustained increase in both MAP (factor time: $\mathrm{F}_{(19,200)}=19, P<0.0001$ ), HR (factor time:
$\left.\mathrm{F}_{(19,200)}=30, P<0.0001\right)$, and plasma corticosterone concentration (factor time: $\mathrm{F}_{(2,30)}=23, P<0.0001$ ) (Fig. 2). Moreover, restraint decreased the tail skin temperature (factor time: $\mathrm{F}_{(8,90)}=8$, $P<0.0001$ ) (Fig. 2). Local microinjection of $\mathrm{CoCl}_{2}$ into the LPO enhanced restraint-evoked increase in HR (factor treatment: $\mathrm{F}_{(1,200)}=14, P<0.0003$ ) and plasma corticosterone (factor treatment: $\left.\mathrm{F}_{(1,39)}=14, P<0.001\right)$, while the pressor response to stress was decreased (factor treatment: $\mathrm{F}_{(1,200)}=19, P<0.0001$ ) (Fig. 2). Furthermore, there was a significant time $\mathrm{x}$ treatment interaction for $\operatorname{MAP}\left(\mathrm{F}_{(19,200)}=2, P<0.006\right)$ and plasma corticosterone $\left(\mathrm{F}_{(2,39)}=4\right.$, $P<0.03)$ measurements, but not for the HR response $\left(\mathrm{F}_{(19,200)}=0.7\right.$, $P>0.05)$. LPO neurotransmission inhibition did not affect the drop in tail skin temperature (factor treatment: $\mathrm{F}_{(1,90)}=0.01, P>0.05$ ) (Fig. 2). Microinjection of $\mathrm{CoCl}_{2}$ into structures surrounding the LPO such as substantia innominate, ventral pallidum and nucleus of the horizontal limb of the diagonal band did not affect the restraint-evoked changes on either MAP $\left(\mathrm{F}_{(1160)}=0.2, P>0.05\right)$, HR $\left(\mathrm{F}_{(1160)}=0.7\right.$, $P>0.05)$ or tail skin temperature $\left(\mathrm{F}_{(1,72)}=0.02, P>0.05\right)$.

Representative experimental recordings showing the effect of the microinjection of vehicle or $\mathrm{CoCl}_{2}$ into the $\mathrm{LPO}$ on the cardiovascular responses evoked by the restraint stress are presented in Fig. 3.

\section{Discussion}

The present study provides the first evidence for the involvement of the LPO on physiological adjustments during exposure to psychological stress. We observed that bilateral microinjection of the nonselective synaptic blocker $\mathrm{CoCl}_{2}$ into the LPO reduced the rise in arterial pressure and enhanced the tachycardiac response and the increase of plasma corticosterone concentration induced by an acute session of restraint stress. The restraint-evoked fall in tail skin temperature was not affected by chemical inhibition of the LPO.

Present findings corroborate previous results demonstrating that neurons within the LPO provide an inhibitory drive toward HPA axis and decrease HR [14,16]. Nevertheless, unexpectedly, our results indicated that LPO oppositely modulated the pressor and tachycardiac responses to restraint stress. These findings are in line with previous results demonstrating that microinjection of the cholinergic agonist carbachol into the LPO evoked opposite changes on blood pressure (increase) and HR (decrease) [21]. The existence of specific neuronal pathways controlling autonomic activity to different organs provides the structural substrate for differences in role of the LPO in modulating restraint-evoked cardiovascular responses [22]. Accordingly, findings in humans and animals have indicated regionally differentiated changes in sympathetic nerve activity $[5,23]$. Therefore, the LPO can be part of different neural pathways in the brain controlling the pressor and tachycardiac responses to stress.

Previous studies demonstrated that neurons within the LPO provide an inhibitory drive toward tail sympathetic nerve activity [15], thus contributing to cutaneous vasodilatation and increase in tail skin temperature [14]. In this regard, the LPO has been implicated in thermoregulatory responses against heat [24]. Although present findings do not support a role of the LPO in sympathetic-mediated cutaneous vasoconstriction during stress, we cannot completely discard

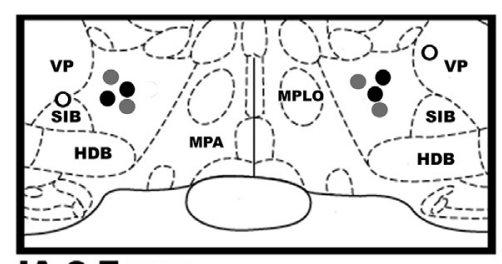

IA $8.7 \mathrm{~mm}$

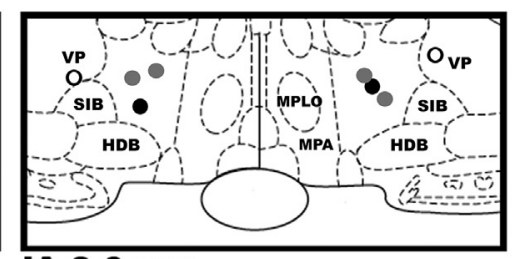

IA $8.6 \mathrm{~mm}$

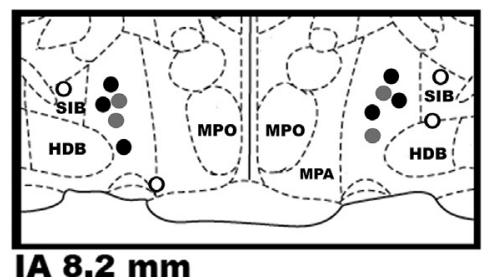

IA $8.2 \mathrm{~mm}$

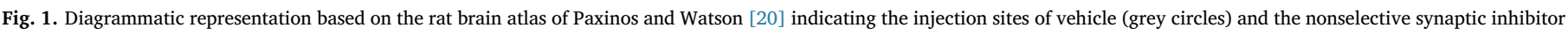

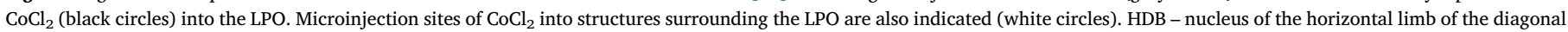
band; IA - interaural coordinate; MPA - medial preoptic area; MPO - medial preoptic nucleus; SIB - substantia innominate/basal part; VP - ventral pallidum. 

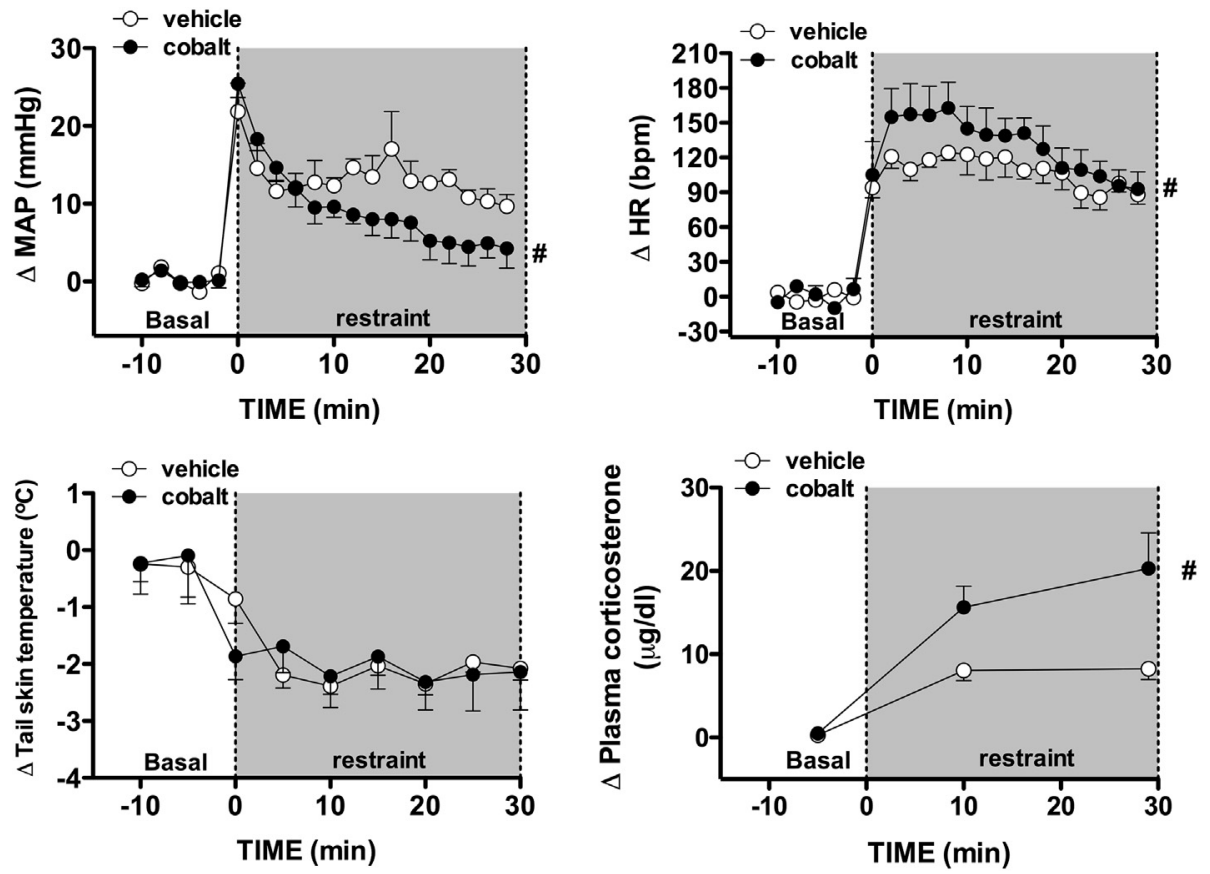

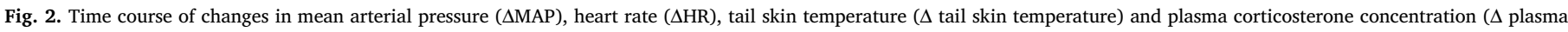

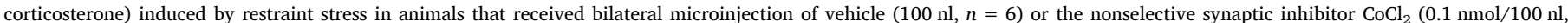

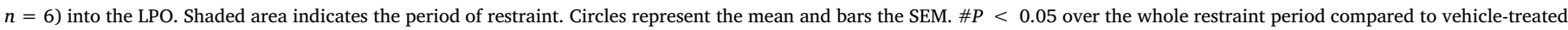
animals, ANOVA followed by Bonferroni post-hoc test.

an involvement of this structure in sympathetic-mediated cutaneous vasoconstriction during stress. For instance, it was previously suggested that the sympathetic-mediated response in the cutaneous temperature reaches its ceiling effect during stress [6], thus precluding the observation of facilitation of this response. Therefore, further studies are necessary to clarify a possible involvement of the LPO in control of cutaneous vasoconstriction during stress.

The activation of the HPA axis is a primary neuroendocrine response during aversive threats [2]. Studies combining retrograde neuronal tracing with Fos immunocytochemistry (marker of neuronal activity) revealed that neurons within the LPO retrogradely labeled from the PVN were activated following exposure to stress [25]. Furthermore, it has been reported that preoptic area sends GABAergic projections to the PVN $[2,12,26]$. In fact, only a minor part of PVN-projecting neurons in the LPO were identified as glutamatergic [27]. Collectively, these results provide evidence that inhibitory influence of the LPO in restraint-evoked elevation of plasma corticosterone may be mediated by a local release of GABA in neurons containing corticotropinreleasing hormone (CRH) into the PVN, which in turn blunt HPA axis activation. This idea is further reinforced by results showing that local microinjection of the $\mathrm{GABA}_{\mathrm{A}}$ antagonist bicuculline into the PVN enhanced stress-evoked corticosterone response, whereas the $\mathrm{GABA}_{\mathrm{A}}$ agonist muscimol blunted this response [12].
Both the sympathetic and the parasympathetic nervous system participate in the control of cardiovascular function during emotional stress [4]. For instance, parasympathetic blockers increase the stressevoked tachycardiac response, whereas this response is reduced by blockade of cardiac sympathetic activity $[28,29]$, thus indicating a concomitant increase of both sympathetic and parasympathetic tone to the heart during stress. Also, aversive threat evokes a sympatheticmediated vasoconstriction in splanchnic, renal, and cutaneous vascular territories [30], which contribute to the increase in the blood pressure [29]. The vasoconstriction in cutaneous beds reduces the local blood flow [31], which in turn evokes a rapid drop in the skin temperature [6-8].

$\mathrm{CoCl}_{2}$ reduces presynaptic $\mathrm{Ca}^{2+}$ influxes, thus leading to a nonselective inhibition of neurotransmitter release and consequent synaptic blockage [43]. Therefore, the absence of changes on baseline parameters indicates that the set of inputs to the LPO are not involved in tonically controlling cardiovascular function and HPA activity. Nevertheless, the changes in stress-evoked cardiovascular and corticosterone responses following $\mathrm{LPO}$ treatment with $\mathrm{CoCl}_{2}$ suggest activation of LPO afferences during aversive threats, which in turn activate outputs from LPO to cardiac, vascular and neuroendocrine centers. Regarding the possible output pathways, the LPO projects to medullary (e.g., rostral medullary raphe) and hypothalamic (e.g., PVN) regions
VEHICLE

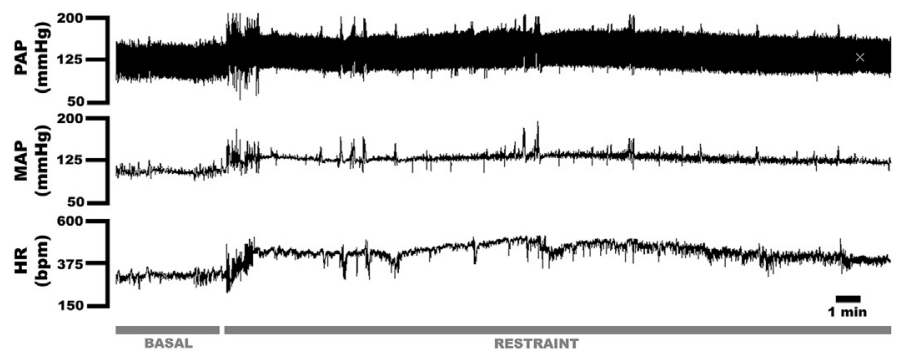

COBALT

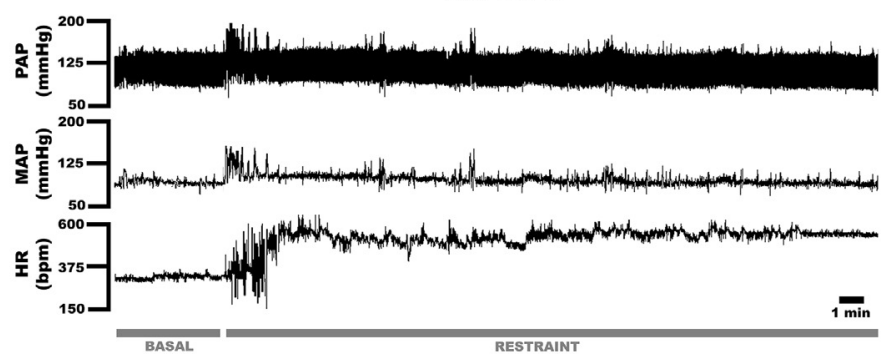

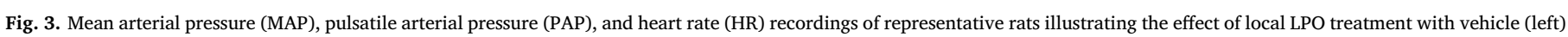
or the nonselective synaptic inhibitor $\mathrm{CoCl}_{2}$ (right) before and during the restraint. 
containing sympathetic premotor neurons [25,27,32]. All nuclei and areas of the preoptic area, including the LPO, also densely innervate the dorsomedial hypothalamic nucleus [33], which is an important sympatoexcitatory site involved in physiological and behavioral responses to aversive stimuli $[5,34,35]$. Modulation of parasympathetic activity by neurons within the PVN has also been suggested [36]. Therefore, LPO may modulates the cardiac response during stress by stimulating inhibitory drive to sympathetic premotor neurons and/or stimulating facilitatory inputs to vagal neurons. Connections from the LPO to regions containing sympathetic premotor neurons could be the neural substrate for the facilitatory influence of the LPO on the pressor response to stress.

The LPO receives inputs from limbic forebrain structures such as the prefrontal cortex, amygdala, and lateral and medial septum [9]. There is evidence of a role for these limbic structures in stress-evoked autonomic and neuroendocrine responses [37-42]. However, these structures have little direct anatomical connections with primary stress effector regions (i.e., the PVN, brainstem, and spinal cord) [2,12], so that intervening connections are required to relay limbic inputs and physiological responses [2,12]. Therefore, present findings provide initial evidence that the LPO may serves as a relay site that integrates limbic processing of emotional information with elaboration of autonomic/neuroendocrine responses.

In summary, the present results provide evidence of an involvement of the LPO in physiological adjustments during emotional stress. Our data suggest that this structure mediates the arterial pressure increase, whereas tachycardia and the increase of plasma corticosterone concentration during aversive threats are inhibited by the LPO.

\section{Acknowledgments}

The authors wish to thank Elisabete Z. P. Lepera, Rosana F. P. Silva, Lucas Barretto de Souza, and Taciana R.S. Pollo for technical assistance. The present research was supported by São Paulo Research Foundation (FAPESP) grants \#2012/14376-0, 2012/50549-6; and 2015/05922-9; National Counsel of Technological and Scientific Development (CNPq) grant \#456405/2014-3; and Scientific Support and Development Program of School of Pharmaceutical Sciences (UNESP). Josiane O. Duarte and Karina S. Gomes received a FAPESP scholarship (proc. 2012/01888-2 and 2013/03445-4, respectively). Ricardo Nunes-deSouza (305597/2012-4) and Carlos Crestani (305583/2015-8) are CNPq research fellow.

\section{References}

[1] P. Sterling, Allostasis: a model of predictive regulation, Physiol. Behav. 106 (2012) $5-15$.

[2] Y.M. Ulrich-Lai, J.P. Herman, Neural regulation of endocrine and autonomic stress responses, Nat. Rev. Neurosci. 10 (2009) 397-409.

[3] R.A. Dampney, J. Horiuchi, L.M. McDowall, Hypothalamic mechanisms coordinating cardiorespiratory function during exercise and defensive behaviour, Auton. Neurosci. 142 (2008) 3-10.

[4] C.C. Crestani, Emotional stress and cardiovascular complications in animal models: a review of the influence of stress type, Front. Physiol. 7 (2016) 251.

[5] R.A. Dampney, Central mechanisms regulating coordinated cardiovascular and respiratory function during stress and arousal, Am. J. Phys. Regul. Integr. Comp. Phys. 309 (2015) R429-R443.

[6] C. Busnardo, F.H. Alves, C.C. Crestani, A.A. Scopinho, L.B. Resstel, F.M. Correa, Paraventricular nucleus of the hypothalamus glutamate neurotransmission modulates autonomic, neuroendocrine and behavioral responses to acute restraint stress in rats, Eur. Neuropsychopharmacol. 23 (2013) 1611-1622.

[7] M.K. Gouveia, T.T. Miguel, C. Busnardo, A.A. Scopinho, F.M. Correa, R.L. Nunes-deSouza, et al., Dissociation in control of physiological and behavioral responses to emotional stress by cholinergic neurotransmission in the bed nucleus of the stria terminalis in rats, Neuropharmacology 101 (2016) 379-388.

[8] D.M. Vianna, P. Carrive, Changes in cutaneous and body temperature during and after conditioned fear to context in the rat, Eur. J. Neurosci. 21 (2005) 2505-2512.

[9] M.J. Wayner, F.C. Barone, S.L. Scharoun, R. Guevara-Aguilar, H.U. AguilarBaturoni, Limbic connections to the lateral preoptic area: a horseradish peroxidase study in the rat, Neurosci. Biobehav. Rev. 7 (1983) 375-384.

[10] K. Briski, E. Gillen, Differential distribution of Fos expression within the male rat preoptic area and hypothalamus in response to physical vs. psychological stress,
Brain Res. Bull. 55 (2001) 401-408.

[11] W.E. Cullinan, J.P. Herman, D.F. Battaglia, H. Akil, S.J. Watson, Pattern and time course of immediate early gene expression in rat brain following acute stress, Neuroscience 64 (1995) 477-505.

[12] W.E. Cullinan, D.R. Ziegler, J.P. Herman, Functional role of local GABAergic influences on the HPA axis, Brain Struct. Funct. 213 (2008) 63-72.

[13] B. Myers, Corticolimbic regulation of cardiovascular responses to stress, Physiol. Behav. (2016).

[14] T. Osaka, Thermoregulatory responses elicited by microinjection of L-glutamate and its interaction with thermogenic effects of GABA and prostaglandin E2 in the preoptic area, Neuroscience 226 (2012) 156-164.

[15] M. Tanaka, M.J. McKinley, R.M. McAllen, Roles of two preoptic cell groups in tonic and febrile control of rat tail sympathetic fibers, Am. J. Phys. Regul. Integr. Comp. Phys. 296 (2009) R1248-R1257.

[16] D.V. Zaretsky, J.L. Hunt, M.V. Zaretskaia, J.A. DiMicco, Microinjection of prostaglandin E2 and muscimol into the preoptic area in conscious rats: comparison of effects on plasma adrenocorticotrophic hormone (ACTH), body temperature, locomotor activity, and cardiovascular function, Neurosci. Lett. 397 (2006) 291-296.

[17] A.C. Campos, M.V. Fogaca, D.C. Aguiar, F.S. Guimaraes, Animal models of anxiety disorders and stress, Rev. Bras. Psiquiatr. 35 (Suppl. 2) (2013) S101-S111.

[18] L.A. Oliveira, J. Almeida, R. Benini, C.C. Crestani, CRF1 and CRF2 receptors in the bed nucleus of the stria terminalis modulate the cardiovascular responses to acute restraint stress in rats, Pharmacol. Res. 95-96 (2015) 53-62.

[19] Z. Sarnyai, E. Biro, B. Penke, G. Telegdy, The cocaine-induced elevation of plasma corticosterone is mediated by endogenous corticotropin-releasing factor (CRF) in rats, Brain Res. 589 (1992) 154-156.

[20] G. Paxinos, C. Watson, The Rat Brain in Stereotaxic Coordinates, Academic Press, Sidney, Australia, 1997.

[21] P.C. Goncalves, M.B. Alves, J.E. Silveira, W.A. Saad, L.A. Camargo, A. Renzi, et al., Effect of AV3V lesion on the cardiovascular, fluid, and electrolytic changes induced by activation of the lateral preoptic area, Physiol. Behav. 52 (1992) 173-177.

[22] S.F. Morrison, Differential control of sympathetic outflow, Am. J. Phys. Regul. Integr. Comp. Phys. 281 (2001) R683-R698.

[23] M. Yoshimoto, K. Nagata, K. Miki, Differential control of renal and lumbar sympathetic nerve activity during freezing behavior in conscious rats, Am. J. Phys, Regul. Integr. Comp. Phys. 299 (2010) R1114-R1120.

[24] R. Srividya, H.N. Mallick, V.M. Kumar, Differences in the effects of medial and lateral preoptic lesions on thermoregulation and sleep in rats, Neuroscience 139 (2006) 853-864.

[25] W.E. Cullinan, D.L. Helmreich, S.J. Watson, Fos expression in forebrain afferents to the hypothalamic paraventricular nucleus following swim stress, J. Comp. Neurol. 368 (1996) 88-99.

[26] J.P. Herman, H. Figueiredo, N.K. Mueller, Y. Ulrich-Lai, M.M. Ostrander, D.C. Choi, et al., Central mechanisms of stress integration: hierarchical circuitry controlling hypothalamo-pituitary-adrenocortical responsiveness, Front. Neuroendocrinol. 24 (2003) 151-180.

[27] Y.M. Ulrich-Lai, K.R. Jones, D.R. Ziegler, W.E. Cullinan, J.P. Herman, Forebrain origins of glutamatergic innervation to the rat paraventricular nucleus of the hypothalamus: differential inputs to the anterior versus posterior subregions, J. Comp. Neurol. 519 (2011) 1301-1319.

[28] P. Carrive, Dual activation of cardiac sympathetic and parasympathetic components during conditioned fear to context in the rat, Clin. Exp. Pharmacol. Physiol. 33 (2006) 1251-1254.

[29] D.G. Dos Reis, E.A. Fortaleza, R.F. Tavares, F.M. Correa, Role of the autonomic nervous system and baroreflex in stress-evoked cardiovascular responses in rats, Stress 17 (2014) 362-372.

[30] Z.Q. Zhang, C. Julien, C. Barres, Baroreceptor modulation of regional haemodynamic responses to acute stress in rat, J. Auton. Nerv. Syst. 60 (1996) 23-30.

[31] W.W. Blessing, Lower brainstem pathways regulating sympathetically mediated changes in cutaneous blood flow, Cell. Mol. Neurobiol. 23 (2003) 527-538.

[32] K. Yoshida, X. Li, G. Cano, M. Lazarus, C.B. Saper, Parallel preoptic pathways for thermoregulation, J. Neurosci. 29 (2009) 11954-11964.

[33] R.H. Thompson, L.W. Swanson, Organization of inputs to the dorsomedial nucleus of the hypothalamus: a reexamination with Fluorogold and PHAL in the rat, Brain Res. Brain Res. Rev. 27 (1998) 89-118.

[34] J.A. DiMicco, B.C. Samuels, M.V. Zaretskaia, D.V. Zaretsky, The dorsomedial hypothalamus and the response to stress: part renaissance, part revolution, Pharmacol. Biochem. Behav. 71 (2002) 469-480.

[35] M.A. Fontes, C.H. Xavier, R.C. de Menezes, J.A. Dimicco, The dorsomedial hypothalamus and the central pathways involved in the cardiovascular response to emotional stress, Neuroscience 184 (2011) 64-74.

[36] C.C. Crestani, F.H. Alves, C. Busnardo, L.B. Resstel, F.M. Correa, N-methyl-Daspartate glutamate receptors in the hypothalamic paraventricular nucleus modulate cardiac component of the baroreflex in unanesthetized rats, Neurosci. Res. 67 (2010) 317-326.

[37] S. Bhatnagar, C. Vining, K. Denski, Regulation of chronic stress-induced changes in hypothalamic-pituitary-adrenal activity by the basolateral amygdala, Ann. N. Y. Acad. Sci. 1032 (2004) 315-319.

[38] E.A. Fortaleza, R.F. Tavares, F.M. Correa, The medial amygdaloid nucleus modulates cardiovascular responses to acute restraint in rats, Neuroscience 159 (2009) 717-726.

[39] J.J. Radley, C.M. Arias, P.E. Sawchenko, Regional differentiation of the medial prefrontal cortex in regulating adaptive responses to acute emotional stress, $\mathrm{J}$. Neurosci. 26 (2006) 12967-12976.

[40] D.G. Reis, A.A. Scopinho, F.S. Guimaraes, F.M. Correa, L.B. Resstel, Behavioral and 
autonomic responses to acute restraint stress are segregated within the lateral septal area of rats, PLoS One 6 (2011) e23171.

[41] G.M. Singewald, A. Rjabokon, N. Singewald, K. Ebner, The modulatory role of the lateral septum on neuroendocrine and behavioral stress responses,

Neuropsychopharmacology 36 (2011) 793-804.
[42] R.F. Tavares, F.M. Correa, L.B. Resstel, Opposite role of infralimbic and prelimbic cortex in the tachycardiac response evoked by acute restraint stress in rats, J. Neurosci. Res. 87 (2009) 2601-2607.

[43] R. Kretz, Local cobalt injection: a method to discriminate presynaptic axonal from postsynaptic neuronal activity, J. Neurosci. Methods 11 (1984) 129-135. 